\title{
Pulmonary atresia with intact ventricular septum and critical pulmonary stenosis presenting in first month of life
}

\section{Investigation and surgical results}

\author{
G. A. H. Miller, M. Restifo, ${ }^{1}$ E. A. Shinebourne, M. Paneth, M. C. Joseph, S. C. Lennox, \\ and I. H. Kerr \\ From the Brompton Hospital, London
}

The results of investigation and surgical treatment of $I 7$ neonates with intact septum pulmonary atresia and 5 with critical pulmonary valve stenosis are presented. Twenty-one patients presented and were catheterized at less than 9 days of age and $I$ at $I 6$ days. A clear division into 2 types of pulmonary atresia depending on right ventricular cavity size, presence of myocardial sinusoids, and degree of tricuspid regurgitation was not possible. In addition, 3 patients with the features of intact septum pulmonary atresia appeared to have a pin-point opening in the pulmonary valve. It is suggested that such patients merge into a further group with critical pulmonary valve stenosis presenting in the first month of life. Patients could not be distinguished on radiographic, electrocardiographic, or haemodynamic grounds but only on the basis of right ventricular angiocardiograms. We question the view that pulmonary valvotomy alone is ever the correct treatment for pulmonary atresia with intact septum even when the right ventricle is large - in contrast all patients with critical pulmonary stenosis did well after open pulmonary valvotomy.

Patients with pulmonary atresia and intact ventricular septum have been classified into two groups according to the size of the right ventricle (Greenwold et al., 1956; Davignon et al., 196Ib). The importance of this classification is that type II pulmonary atresia, with a large right ventricular cavity, has been thought likely to be correctable by pulmonary valvotomy and to carry a better prognosis than type I pulmonary atresia with an inadequate right ventricle (Greenwold et al., 1956). Review of the published reports and our own experience do not altogether support this view; thus, the classification into two types has been shown to be an over-simplification (Gersony et al., 1967) while the multitude of surgical techniques which have been employed reflects uncertainty about the correct approach and, in particular, about the ability of the right ventricle to sustain adequate pulmonary flow and its ability to develop. We report here our experience of 17

Received II May 1972.

1 Present address: Cardiology Department, Georgetown University Hospital, 3800 Reservoir Road NW, Washington, DC 20007, U.S.A. neonates, with pulmonary atresia and intact ventricular septum; in addition, details are given of 5 neonates with critical pulmonary valve stenosis presenting at the same age. The very different surgical results in the latter group despite an almost identical haemodynamic disturbance emphasize the importance of high quality right ventricular angiocardiography in distinguishing the two conditions - not so much to determine right ventricular size as to detect patency of the pulmonary valve.

\section{Patients}

The patients form two main groups; 17 with pulmonary atresia and intact ventricular septum and 5 with critical pulmonary valve stenosis. They were all investigated between October 1967 and May 1972; those with pulmonary atresia represent a prevalence of just over I per cent of all types of congenital heart disease seen at this hospital during this time and of between 6 and 7 per cent of all forms of congenital heart disease in neonates.

\section{Methods}

Cardiac catheterization was performed using a conven- 
tional catheter/manometer system. Oxygen saturation was measured by reflection oximetry. ${ }^{1}$ Angiocardiography was performed with injection of contrast medium into the right ventricle in all patients. In all but 3 patients (Cases 8, IO, and II), in whom cineangiocardiography was employed, rapid $(6 / \mathrm{sec})$ biplane serial films were taken.

\section{Results}

\section{Angiographic appearances}

Patients were allocated to one of three groups on the basis of the right ventricular (RV) angiocardiograms (Table I).

Group I: Pulmonary atresia with intact ventricular septum and small right ventricular cavity This group was subdivided into those with slight or absent tricuspid regurgitation, and those with the severe form.

a) With slight or absent tricuspid regurgitation (Fig. Ia) (8 patients; $4 \mathrm{~F}, 4 \mathrm{M}$, age at catheterization I to 8 days) Myocardial sinusoids were present in all patients in this group and were conspicuous in 5. In some instances sinusoids were seen to fill the coronary arteries with retrograde opacification of

1 Kipp and Zonen, Delft, Holland. the aorta (Fig. Ib). These patients correspond to type I pulmonary atresia of Greenwold et al. (I956).

b) With severe tricuspid regurgitation (7 patients; 3 F, 4 M, age at catheterization I to 6 days) Myocardial sinusoids were absent in 3 of the 7 patients and obvious in only $\mathbf{I}$. These patients are intermediate between type I and type II pulmonary atresia of Greenwold et al. (1956) in that though they had obvious tricuspid regurgitation and, usually, less obvious sinusoids, they still had a small right ventricular cavity.

Group 2: Pulmonary atresia with intact ventricular septum and large right ventricular cavity (Fig. 2) (2 patients, both female; age at catheterization 2 days and 5 days) Myocardial sinusoids were absent in both patients; tricuspid regurgitation was slight in I and severe in the other patient. These patients resemble type II pulmonary atresia of Greenwold et al. (1956) but in both patients there appeared to be faint early opacification of the pulmonary artery, suggesting pin-point patency of the pulmonary valve. At open pulmonary valvotomy a minute pin-hole was seen in one patient but could not be confirmed in the other.

TABLE I Plain chest $\mathrm{x}$-ray and angiographic findings

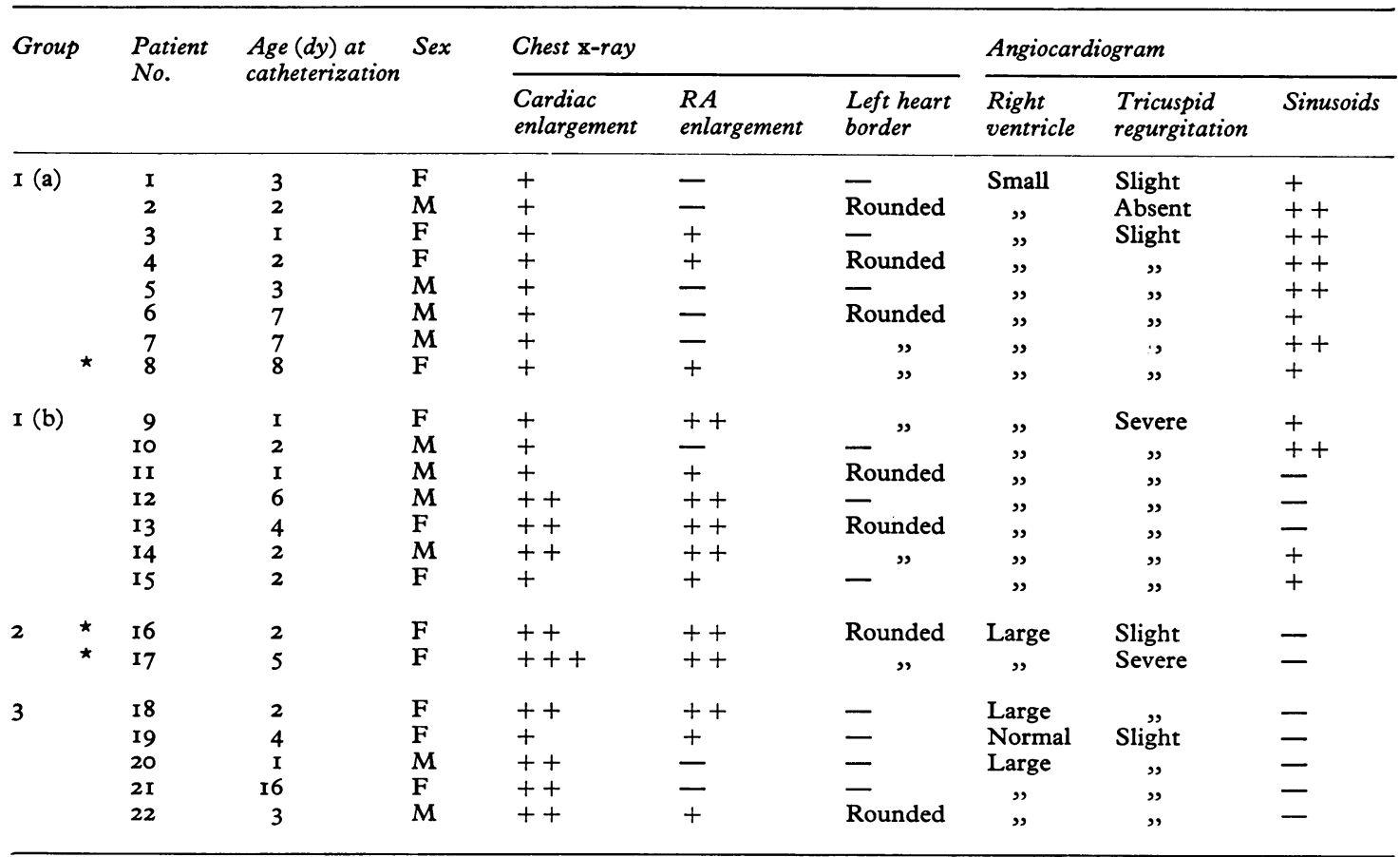

$\star$ Surgical or angiographic evidence of pin-point patency of pulmonary valve. 


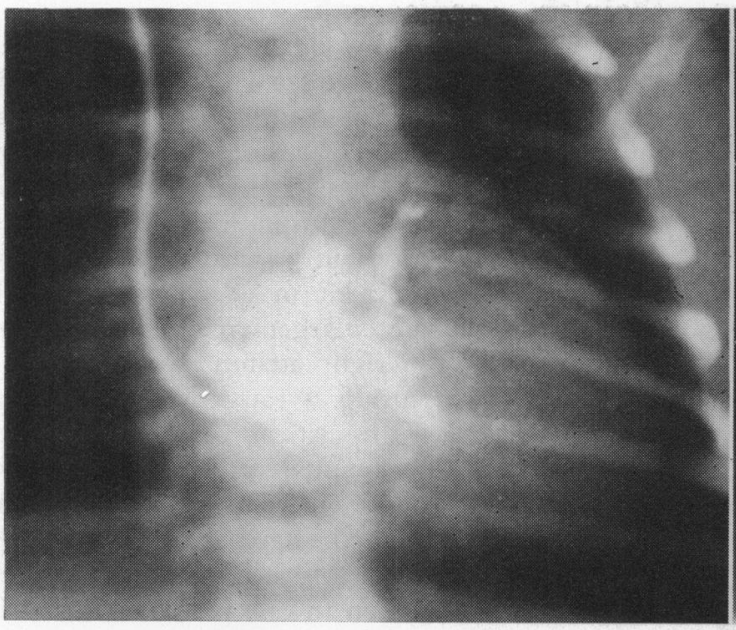

a

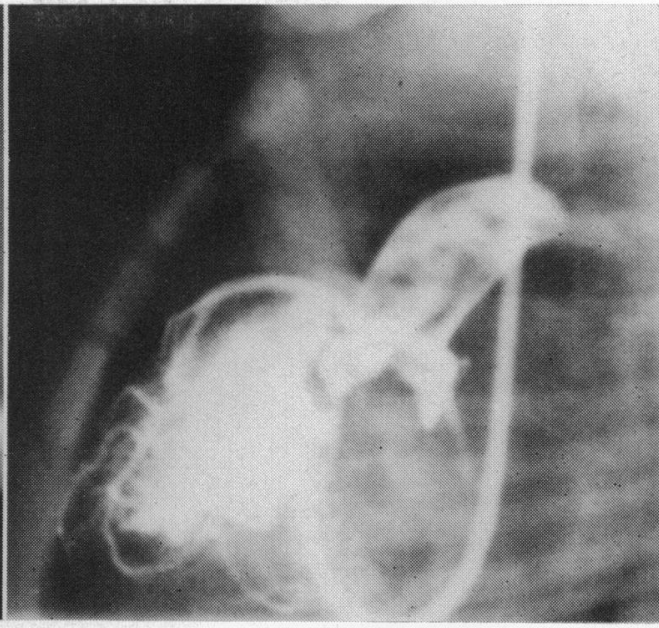

$\mathrm{b}$

FIG. I (a) Case 3. Pulmonary atresia. Right ventricular angiocardiogram (AP projection) showing a small right ventricular cavity and myocardial sinusoids. (b) Case 5. Pulmonary atresia. Right ventricular angiocardiogram (lateral projection). Obvious myocardial sinusoids. There is retrograde flow from these sinusoids via the right coronary artery resulting in dense opacification of the aorta.

These patients might be considered examples of critical pulmonary stenosis; however, the angiographic appearances differed from those in group 3 patients in that early opacification of the pulmonary artery was difficult to detect and never sufficient to outline its size. In one other patient (Case 8, in group I (a)) pin-point patency of the pulmonary valve was detected at operation despite the angio-

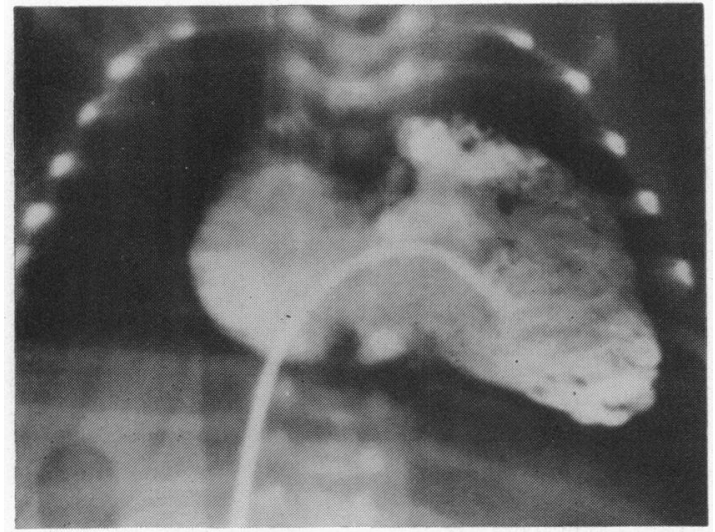

FIG. 2 Case No. 17. Pulmonary atresia. Right ventricular angiocardiogram (AP projection). Large right ventricular cavity and severe tricuspid regurgitation. No myocardial sinusoids. graphic appearances of pulmonary atresia with myocardial sinusoids.

Group 3: Critical pulmonary valve stenosis ( 5 patients ; 2 F, $3 \mathrm{M}$, age at catheterization I to 16 days) The right ventricular cavity was normal sized or large and was heavily trabeculated in all patients, none had myocardial sinusoids, and in all there was obvious early opacification of the pulmonary artery which was seen to be of approximately normal diameter. Tricuspid regurgitation was slight in 4 patients and obvious in I (Fig. 3).

\section{Electrocardiogram}

The electrocardiogram was unhelpful in distinguishing between patients in groups I (a), I (b), and 2. Two electrocardiographic patterns were found: (i) normal for age and (ii) diminution of right-sided forces (Liebman, I968). Unfortunately only one cardiogram was available for review in group 2 (large right ventricle) - this showed diminution of rightsided forces, but this pattern was also seen in 6 of the 13 available electrocardiograms in groups I (a) and $I(b)$ and in one patient with critical pulmonary stenosis.

In 4 of the 5 patients with critical pulmonary stenosis (group 3) the mean frontal QRS axis was between $+120^{\circ}$ and $+140^{\circ}$, whereas only one patient with pulmonary atresia (Case 6, in group I (a)) had an axis as far to the right as $120^{\circ}$ (Fig. 4); 


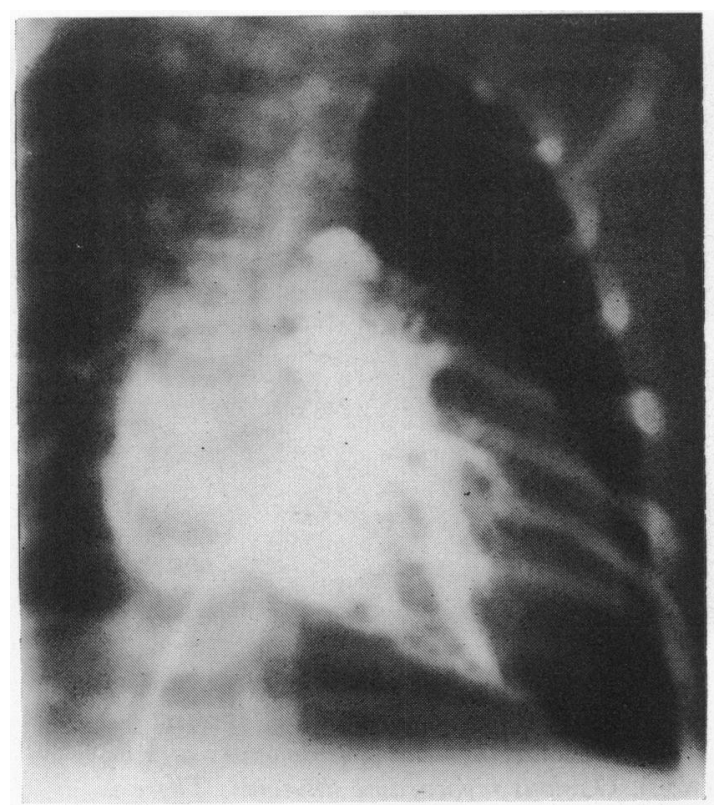

FIG. 3 Case 20. Critical pulmonary valve stenosis, aged $I$ day. Right ventricular angiocardiogram ( $A P$ projection). Large right ventricular cavity with heavy trabeculation. There is obvious early opacification of the pulmonary artery which is of normal or near-normal diameter. There is slight tricuspid regurgitation.

MEAN FRONTAL QRS AXIS

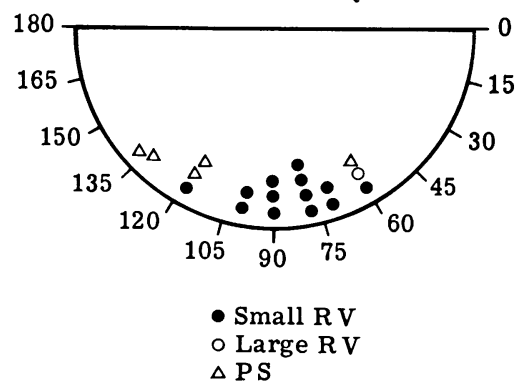

FIG. 4 Mean frontal $Q R S$ axis for I 3 patients with pulmonary atresia and small right ventricle, $I$ with pulmonary atresia and large right ventricle, and 5 with critical pulmonary stenosis.

however, in one patient in group 3 the mean frontal QRS axis was only $+60^{\circ}$ and this was the only patient in this group in whom the pattern of diminished right-sided forces was seen.

\section{Plain chest radiograph}

In all patients there was oligaemia of the lung fields and some degree of cardiac enlargement. Cardiac enlargement was slight in group I (a) patients and the right atrial shadow prominent in only 3 . In the patients in group I (b) with a small right ventricle but severe tricuspid regurgitation cardiac enlargement was conspicuous in 3 of the 7 and the right atrial shadow prominent in all but one. Finally, conspicuous cardiac enlargement and considerable prominence of the right atrium was a feature of both patients in group 2 (large right ventricular cavity). Patients with critical pulmonary stenosis (group 3) had conspicuous cardiac enlargement in 4 of the 5 and a prominent right atrial shadow in 3 .

A peculiarly rounded shape to the left cardiac border (Fig. 5) was a feature of the group $I$ and 2 cases but was also seen in one patient with critical pulmonary stenosis (group 3).

\section{Haemodynamic findings}

Right ventricular hypertension (exceeding systemic pressure in all but 2 patients) was an invariable finding, as was right-to-left interatrial shunting with arterial desaturation (ranging from $20-63 \%$ in patients in groups I (a), I (b), and 2 and from 20$67 \%$ in patients in group 3 with critical pulmonary stenosis). Neither the absolute magnitude of right ventricular systolic pressure nor the right ventricular systolic/systemic systolic ratio served to distinguish between patients in the different groups. The

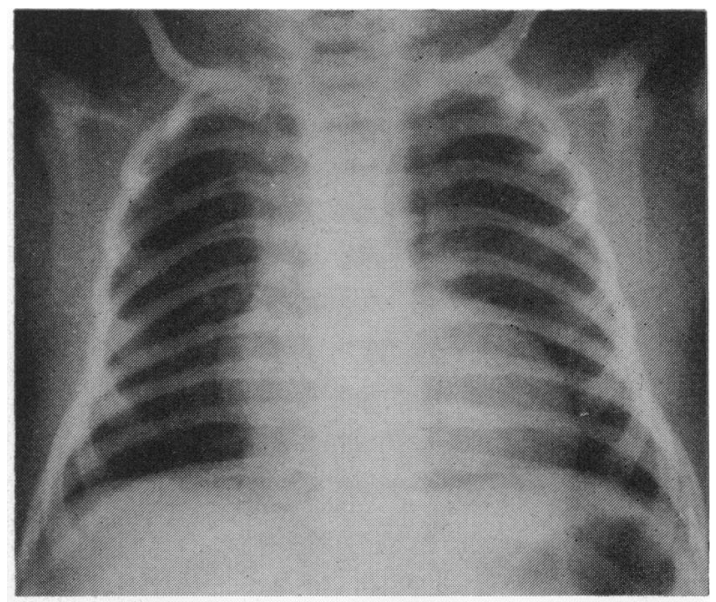

FIG. 5 Case 4. Pulmonary atresia with small right ventricle and only slight tricuspid regurgitation. Plain chest $\mathrm{x}$-ray showing pulmonary oligaemia, slight cardiac and right atrial enlargement, and 'rounded' left cardiac border. 
presence of conspicuous tricuspid regurgitation was not associated with significantly lower right ventricular systolic pressures. The right ventricular end-diastolic pressures were equally unhelpful in distinguishing between the various groups.

\section{Results of operation}

First operation (Tables 2 and 3 )

Operation was carried out within 4 days of diagnostic catheterization in all but one patient. This patient (Case 7), with a small right ventricle, pulmonary atresia, and persistent ductus arteriosus, was reasonably well initially, but at 4 months of age

TABLE 2 Results of operation - type of abnormality

\begin{tabular}{lll}
\hline $\begin{array}{l}\text { No. of } \\
\text { patients }\end{array}$ & $\begin{array}{l}\text { Hospital } \\
\text { death }\end{array}$ & $\begin{array}{l}\text { Late } \\
\text { death }\end{array}$
\end{tabular}$\quad$ 'Good' result

Pulmonary atresia with small right ventricle and slight or

absent tricuspid regurgitation (group I (a))

$8 \quad 3 \quad 3 \quad 25(25)$

Follow-up $7 \frac{1}{2} \mathrm{mth}$, $18 \mathrm{mth}$

Pulmonary atresia with small right ventricle and conspicuous tricuspid regurgitation (group I (b))

$\begin{array}{llll}7 & 4 & \text { If } & 2(29 \%) \\ & & \text { Follow-up } 3 \mathrm{mth}, 4 \mathrm{mth}\end{array}$

Pulmonary atresia or (?) pin-point stenosis, large right ventricle (group 2)$$
2 \begin{gathered}
\text { ventricle (group 2) } \\
2
\end{gathered}-
$$

Critical pulmonary stenosis (group 3) $\ddagger$

5 - $\quad$ - $5(100 \%)$

* One patient died at $7 \frac{1}{2}$ months during a second operation designed to achieve complete correction.

† Patient died at $\mathrm{I}$ month after a second operation designed to achieve complete correction.

$¥$ In all patients in this group the operation performed was open pulmonary valvotomy under hypothermia with closure of a patent foramen ovale in 4 of the 5 patients. All patients in this group remain alive and well at 3 years, 3 years, 17 months, 15 months, and 2 months. there was evidence that the ductus was closing and a Waterston shunt ${ }^{1}$ was constructed: he died 2 days later.

Among patients with pulmonary atresia good results were obtained only in patients in groups I (a) and I (b) with a small right ventricle and were associated with a Waterston shunt alone or with a Waterston shunt and atrial septectomy. Though pulmonary valvotomy did not produce a long-term survival in these groups, two patients survived 9 weeks and 3 weeks after a closed and an open pulmonary valvotomy, respectively. ${ }^{2}$

Neither of the two patients with pulmonary atresia and a large right ventricle (group 2) survived operation (open valvotomy with hypothermia).

\section{Second operation (Table 4)}

A second operation was carried out or attempted in 6 patients, including 2 of the 'long-term' survivors. All patients died on the table ( 3 patients, I during induction) or within 24 hours of operation (3 patients).

\section{Discussion}

Patients with intact septum pulmonary atresia have been classified as belonging to two groups. In one (type I) the right ventricular cavity is small, there are conspicuous myocardial sinusoids, and tricuspid regurgitation is absent. In the other (type II) the right ventricle cavity is large, sinusoids are absent, and there is conspicuous tricuspid regurgitation (Greenwold et al., 1956; Davignon et al., 196Ib). Type I and type II pulmonary atresia have been distinguished on electrocardiographic and radio-

\footnotetext{
${ }^{1}$ Right pulmonary artery to ascending aorta.
}

${ }^{2} \mathrm{~A}$ further patient who did not present for catheterization until 45 days of age (and is thus excluded from this study) is still alive and well I year and 9 months after an open pulmonary valvotomy. Angiographically, this patient had a small right ventricle with conspicuous tricuspid regurgitation and no myocardial sinusoids. This patient was also the only patient in whom the interatrial communication was not closed at the time of open pulmonary valvotomy.

TABLE 3 Pulmonary atresia: results of initial operation - type of operation

\begin{tabular}{|c|c|c|c|c|}
\hline Operation & No. of patients & Hospital death & Late death & Good result \\
\hline Waterston shunt & 6 & 3 & 2 (3 wk, $\left.3 \frac{1}{2} \mathrm{mth}\right)$ & I $(17 \%)$ \\
\hline Waterston shunt + atrial septectomy & 4 & 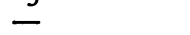 & $\mathrm{I}(\mathrm{I} \mathrm{mth})^{\star}$ & $3(75 \%)$ \\
\hline Pulmonary valvotomy (closed) & 2 & $\mathbf{I}$ & I $(9 \mathrm{wk})$ & $0-$ \\
\hline Pulmonary valvotomy (open, hypothermia) & 4 & 4 & 0 & 0 - \\
\hline Pulmonary valvotomy (closed) + Waterston shunt & I & I & o & $0-$ \\
\hline $\begin{array}{l}\text { Total } \\
(\%)\end{array}$ & 17 & $\stackrel{9}{9})$ & $\begin{array}{l}4 \\
(23 \cdot 5)\end{array}$ & $\begin{array}{l}4 \\
(23 \cdot 5)\end{array}$ \\
\hline
\end{tabular}

* After second operation designed to achieve complete correction. This patient had had a pulmonary valvotomy at the initial operation in addition to a Waterston shunt and atrial septectomy. 
TABLE 4 Pulmonary atresia: details of second operation

\begin{tabular}{|c|c|c|c|}
\hline $\begin{array}{l}\text { Case } \\
\text { No. }\end{array}$ & Operation & $\begin{array}{l}\text { Time after } \\
\text { first operation }\end{array}$ & First operation \\
\hline 3 & $\begin{array}{l}\text { Pulmonary valvotomy (open, hypothermia); closure of patent } \\
\text { foramen ovale }\end{array}$ & 9 wk & Closed pulmonary valvotomy \\
\hline 5 & $\begin{array}{l}\text { Pulmonary valvotomy (open, hypothermia); closure of Water- } \\
\text { ston shunt and of atrial septectomy }\end{array}$ & $7 \frac{1}{2} \mathrm{mth}$ & Waterston shunt + atrial septectomy \\
\hline 7 & Pulmonary valvotomy (open, inflow stasis) & $3 \mathbf{w k}$ & Waterston shunt \\
\hline II & Waterston shunt & I dy & Closed pulmonary valvotomy \\
\hline 12 & Died during induction & $16 \mathrm{dy}$ & $\begin{array}{l}\text { Waterston shunt + closed pulmonary } \\
\text { valvotomy }\end{array}$ \\
\hline 14 & $\begin{array}{l}\text { Pulmonary valvotomy (open, hypothermia); closure of Water- } \\
\text { ston shunt and of atrial septectomy; ligation of persistent } \\
\text { ductus arteriosus }\end{array}$ & I mth & $\begin{array}{l}\text { Waterston shunt + atrial septectomy } \\
\text { + pulmonary valvotomy }\end{array}$ \\
\hline
\end{tabular}

graphic grounds, though the electrocardiogram at least has been shown to be unreliable in the first week of life (Davignon et al., 1961a; Cole et al., 1968; Dhanavaravibul, Nora, and McNamara, 1970) - the age at which the majority of these patients present. Our experience supports the view that in this age group the cardiogram does not distinguish between type I and type II pulmonary atresia and an indistinguishable electrocardiographic pattern may be seen in patients with critical pulmonary stenosis. The plain chest $x$-ray provided some indication of the size of the right ventricle and the degree of tricuspid regurgitation but was not specific for types I and II. In our experience and in that of others (Celermajer et al., I968) the right ventricular pressure did not distinguish between patients with type I or type II pulmonary atresia; indeed, patients with critical pulmonary stenosis were also indistinguishable on haemodynamic grounds alone. Selective right ventricular angiocardiography is the single most helpful investigation, though errors of interpretation have occurred when communicating sinusoids have been mistaken for the border of the right ventricular cavity, leading to an overestimate of cavity size (Dhanavaravibul $e t$ al., 1970). The degree of tricuspid regurgitation may also be overestimated when the catheter is dislocating the tricuspid valve or the injection is made partially into the right atrium.

It may be that the classification of intact septum pulmonary atresia into two groups is an oversimplification (Gersony et al., 1967; Bowman et al., 1971; Murphy et al., 197I). Our own experience supports the view that, as with most biological phenomena, pulmonary atresia with intact ventricular septum forms a spectrum of abnormalities. Thus severe tricuspid regurgitation was not confined to patients with a large right ventricle but was also present in 5 of the 13 with a small right ventricle. Myocardial sinusoids were found only in those with a small right ventricle but were not invariably present even in this group. What is perhaps more important, however, is that 3 patients had all the angiographic (and haemodynamic) features of intact septum pulmonary atresia except for angiographic or surgical evidence of pin-point patency of the pulmonary valve. Two of these patients had a large right ventricle and one a small right ventricle.

It is possible that obstruction at pulmonary valve level may become progressively more severe during fetal life and that on occasion the situation at birth which we recognize as pulmonary atresia may be the end result of this process. In other patients there is still pin-point patency of the pulmonary valve at birth and these patients merge into a third group who, at birth, still have a $\frac{1}{2}-1 \mathrm{~mm}$ opening in the pulmonary valve and are recognized as having critical pulmonary stenosis (Benton et al., 1962; Gersony et al., 1967; Cole et al., 1968). If this thesis is correct, then we may also postulate that the size of the right ventricle (and, possibly, the tricuspid orifice) may reflect flow through the ventricle during intrauterine life. Other indications of the intrauterine flow pattern which might be expected when obstruction at pulmonary valve level has been critical or complete from early fetal life would be (i) an aorta which tapers smoothly and does not exhibit the isthmal narrowing and postductal dilatation normally found at birth (reflecting right-to-left flow across the ductus during fetal life); (ii) a pulmonary artery considerably smaller than the aorta; and (iii) a ductus arteriosus which is small and whose direction might differ from the normal continuous arc between pulmonary artery and descending aorta. Conspicuous development of myocardial sinusoids might also be expected in those patients in whom there has been no egress from the right ventricle during much of fetal life and might therefore be expected in association with a small right ventricular cavity.

Our patients provide some support for this hypo- 
thesis - thus aortic morphology could be determined in II patients; in 8 with complete pulmonary atresia the aorta had the 'adult' morphology without isthmal narrowing. The remaining 3 patients all had either the fetal pattern with isthmal narrowing or a pattern intermediate between this and the adult pattern; 2 of these patients had a pin-point opening in the pulmonary valve, while the third had critical pulmonary stenosis. The pulmonary artery was certainly smaller than the aorta in all patients with pulmonary atresia, while the more normal-sized pulmonary artery was one of the features that distinguished patients with critical pulmonary stenosis.

The importance of determining right ventricular size rests on the assumption that type II pulmonary atresia, with an adequate right ventricular cavity, should be amenable to correction by pulmonary valvotomy and should have a better prognosis (Greenwold et al., 1956). This might be expected to be true whether the right ventricular size was determined by the fetal haemodynamics or was otherwise determined. However, when the reported experience is reviewed to determine whether in fact type II pulmonary atresia carries a better prognosis and can be treated by pulmonary valvotomy, we find conflicting evidence. In 1967, Gersony and co-workers (1967) collected I23 reported cases and found only one survivor (from valvotomy in a patient with type II pulmonary atresia) and added 2 survivors of their own, both of whom had type I pulmonary atresia. More recently, improved operative results have been reported with survival rates of between 19 and 58 per cent (Cole et al., 1968; Dhanavaravibul et al., 1970; Bowman et al., 197I; Shams et al., 1971). Review of the experience of these four groups of authors reveals no survivors with type II pulmonary atresia and only 2 patients surviving pulmonary valvotomy (Bowman et al., 1971; Dhanavaravibul et al., 1970). The best results were obtained by the use of an aortopulmonary shunt, often with creation of an atrial septal defect by septectomy or by balloon septostomy. Since adopting this approach, Shams and co-workers (I97I) obtained 7 survivors of 8 patients whereas none of their previous 30 patients had survived. The proportion of patients with type II (large right ventricle) pulmonary atresia in these 4 series was similar to the 20 to 25 per cent prevalence generally reported and the 12 per cent prevalence in our own series. In sharp contrast are the reports of Murphy and co-workers (197I), Ziegler and Taber (1962), Celermajer and co-workers (1968) and Rook and Gootman (197I). All 3 patients reported by Ziegler and Taber and the 3 reported by Rook and Gootman appeared to have type II pulmonary atresia, and all survived pulmonary valvotomy though 2 required an additional systemic- to-pulmonary shunt (Rook and Gootman, 197I). Of the larger series reported by Celermajer and coworkers (1968) and Murphy and co-workers (197I), all survivors had type II pulmonary atresia and all had a pulmonary valvotomy. The experience of these latter groups of authors is unusual in that the prevalence of type II pulmonary atresia was much higher than generally reported $(60 \%$ of those in whom the right ventricular size was known in Murphy and co-workers' series and $67 \%$ in the series reported by Celermajer and co-workers).

There seems, therefore, to be general agreement that patients with a small or miniscule right ventricle require an aortopulmonary shunt, preferably with creation of an atrial septal defect (Trusler and Fowler, 1970). In contrast, good results can be obtained in patients with critical pulmonary stenosis by pulmonary valvotomy - and this is also our experience (Burnell et al., 1970). Such patients are very similar on haemodynamic and angiographic grounds to patients with type II pulmonary atresia and can only be distinguished by high quality right ventricular angiocardiograms if these show good filling of a normal sized pulmonary artery from the right ventricle. It is possible that some of the good results reported for pulmonary valvotomy in type II pulmonary atresia were examples of critical pulmonary stenosis - certainly we remain unconvinced that pulmonary valvotomy alone is ever the treatment of choice for neonates with pulmonary atresia even when the right ventricle is large or where there may be pin-point patency of the valve revealed by high quality right ventricular angiocardiograms. It may, however, be desirable to inspect the right ventricular outflow tract and, if possible, to perform pulmonary valvotomy at the time of creation of a shunt and atrial septal defect as advocated by Bowman and co-workers (I97I) because these authors have presented evidence suggesting that the right ventricle can increase in size when this is done. Unfortunately, abnormalities of the tricuspid valve are frequent in this condition and may frustrate attempts at complete correction; thus one of our patients progressed well for $7 \frac{1}{2}$ months after atrial septectomy and creation of a Waterston shunt. At the second operation the right ventricular cavity appeared to be of reasonable size but was occupied by a fibrin thrombus; attempts at complete correction were frustrated by near-atresia of the tricuspid valve which was displaced into the right ventricular cavity in an Ebsteinlike fashion. Whether or not the tricuspid valve would have developed as well as the right ventricle had a pulmonary valvotomy been performed at the first operation is unknown, but abnormalities of the tricuspid valve may provide a further bar to eventual complete correction. 


\section{References}

Benton, J. W., Elliott, L. P., Adams, P., Anderson, R. C., Hong, C. Y., and Lester, R. G. (I962). Pulmonary atresia and stenosis with intact ventricular septum. American fournal of Diseases of Children, 104, I6I.

Bowman, F. O., Malm, J. R., Hayes, C. J., Gersony, W. M., and Ellis, K. (I97I). Pulmonary atresia with intact ventricular septum. Fournal of Thoracic and Cardiovascular Surgery, 61, 85 .

Burnell, R. H., Ghadiali, P. E., Joseph, M. C., and Paneth, M. (1970). Management of critical valvular outflow obstruction in neonates. Thorax, $25,116$.

Celermajer, J. M., Bowdler, J. D., Gengos, D. C., Cohen, D. H., and Stuckey, D. S. (1968). Pulmonary valve fusion with intact ventricular septum. American Heart fournal, 76, 452 .

Cole, R. B., Muster, A. J., Lev, M., and Paul, M. H. (1968). Pulmonary atresia with intact ventricular septum. American fournal of Cardiology, 21, 23.

Davignon, A. L., DuShane, J. W., Kinkaid, O. W., and Swan, H. J. C. (1961a). Pulmonary atresia with intact ventricular septum. Report of two cases studied by selective angiocardiography and right heart catheterization. American Heart fournal, 62, 690.

Davignon, A. L., Greenwold, W. E., DuShane, J. W., and Edwards, J. E. (I96Ib). Congenital pulmonary atresia with intact ventricular septum. Clinicopathologic correlation of two anatomic types. American Heart fournal, 62, 591.

Dhanavaravibul, S., Nora, J. J., and McNamara, D. G. (1970). Pulmonary valvular atresia with intact ventricular septum: problems in diagnosis and results of treatment. Fournal of Pediatrics, 77, Ioro.

Gersony, W. M., Bernhard, W. F., Nadas, A. S., and Gross, R. E. (1967). Diagnosis and surgical treatment of infants with critical pulmonary outflow obstruction. Circulation, 35,765 .

Greenwold, W. E., DuShane, J. W., Burchell, H. B., Bruwer, A., and Edwards, J. E. (1956). Congenital pulmonary atresia with intact ventricular septum: two anatomic types (abstract). Circulation, 14, 945.

Liebman, J. (1968). Electrocardiography. In Heart Disease in Infants, Children and Adolescents, p. I83. Ed. by A. J. Moss and F. H. Adams. Williams and Wilkins, Baltimore.

Murphy, D. A., Murphy, D. R., Gibbons, J. E., and Dobell, A. R. C. (197I). Surgical treatment of pulmonary atresia with intact interventricular septum. Fournal of Thoracic and Cardiovascular Surgery, 62, 213.

Rook, G. D., and Gootman, N. (I97I). Pulmonary atresia with intact interventricular septum: operative treatment with survival. American Heart fournal, 81, 476.

Shams, A., Fowler, R. S., Trusler, G. A., Keith, J. D., and Mustard, W. T. (197I). Pulmonary atresia with intact ventricular septum: report of 50 cases. Pediatrics, 47, 370

Trusler, G. A., and Fowler, R. S. (I970). The surgical management of pulmonary atresia with intact ventricular septum and hypoplastic right ventricle. Fournal of Thoracic and Cardiovascular Surgery, 59, 740.

Ziegler, R. F., and Taber, R. E. (1962). Diagnostic criteria and successful surgery in an operable form of complete pulmonary valve atresia (abstract). Circulation, 26, 807.

Requests for reprints to Dr. G. A. H. Miller, Brompton Hospital, Fulham Road, London $\mathrm{SW}_{3} 6 \mathrm{HP}$. 